\title{
Aerodynamics Analysis for an Outdoor Road Cycling Helmet and Air Attack Helmet
}

\author{
M. N. Abdullah, M. K. H. Muda, F. Mustapha, and M. A. Shamsudin
}

\begin{abstract}
The study of aerodynamics is very crucial in the world of cycling. Wind tunnel experiment is conducted on most of cycling equipment that is used by a rider and it is a serious factor in the development of cycling sport. This paper represents the aerodynamics analysis of sport cycling helmet and the comparison between a standard road cycling helmet and Air Attack helmet. The test was conducted in a several constant wind tunnel velocity that best reflects the apparent wind velocity that the rider would experience. The test set collects data for 7 different speeds from $3 \mathrm{~m} / \mathrm{s}$ to $15 \mathrm{~m} / \mathrm{s}$. A data set was recorded for each helmet at two different pitch angles which is $0^{\circ}$ and $25^{\circ}$ angle. The testing result showed that aerodynamic helmets offer drag reduction over a standard road cycling helmet.
\end{abstract}

Index Terms-Aerodynamic drag, cycling, coefficient of drag, helmets, six component balance, wind tunnel.

\section{INTRODUCTION}

The sport of road bicycle racing is unceasingly pushing the boundaries of new knowledge and studying every possible method to surge speed and efficiency. In time-trial cycling, bicycles are made as aerodynamically efficient as the governing rules consent. Blair et al. [1] reported that many of these events are won or lost by only seconds. Small reductions in overall aerodynamic drag can easily save seconds in any of these events, giving the athlete a decisive advantage. During a long bicycle time trial or during the cycling portion of a triathlon, 80 to 90 percent of the power developed by the athlete is used to overcome aerodynamic drag. According to Peter E. Jenkins [2], many aerodynamic helmets have been developed to reduce the aerodynamic drag experienced by cyclists. Though not optimized airfoils, current helmets are designed with a tear drop shape to try and maintain attached air flow. This shape provides a significant drag reduction when the athlete has his or her head up and is looking forward but has adverse effects if the athlete is looking down or riding in a cross-wind. The term drag relates to the resistance of an object as it moves through a fluid and can be represented as a unit of drag force, $D$. Drag force is the summation of both friction and pressure drag. Friction drag, $\mathrm{D}_{\mathrm{f}}$, is produced when a viscous fluid flows over a surface [3]. A comparison of the two is simply illustrated in Fig. 1. Drag on bicycles plays a much larger role than on automobiles, for example, as a rider aboard a bicycle is not a smooth object like a passenger car. An aerodynamically designed car can

Manuscript received May 5, 2015; revised August 5, 2015.

The authors are with the Department of Aerospace Engineering, Universiti Putra Malaysia, 43400 Serdang, Selangor, Malaysia (e-mail: naimabdullah14@gmail.com). have minimal flow separation; therefore most of the drag force will be friction drag and a smaller percentage pressure drag. A passenger car, for example, typically has a drag coefficient in the range of 0.3 to 0.35 . Shahbazi [4] presented that a bicycle and rider are very different in the way drag is produced. The general shape of a rider aboard a bicycle is not streamlined and there are many pockets where air can be trapped and increase drag (Shahbazi, 2007). Meanwhile common aerodynamic drag coefficient values for bicycles can range from 0.6 to 0.8 in racing configurations [5].

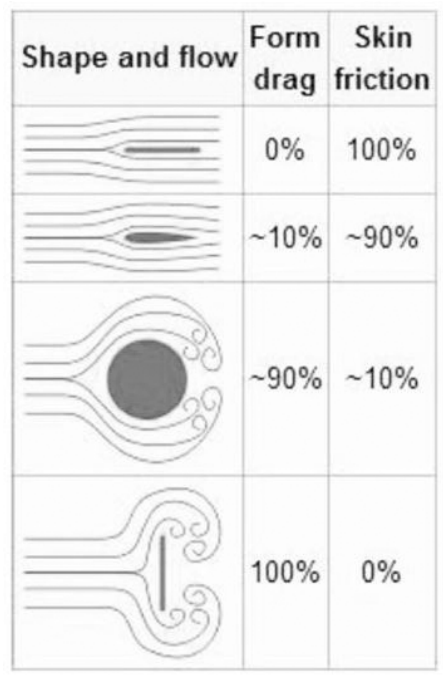

Fig. 1. Form drag vs. friction drag [3].

Previous research by field testing and wind-tunnel experiments by Garcia-Lopez et al. [6] showed that adjustments to the cyclist's position, even minor ones, can result in a decrease of the aerodynamic drag, which indicates the possibility for optimization. In summary, previous research has shown that helmet aerodynamics can play a significant role in performance and that production helmets do not perform well at decreased pitch angles. Current helmet design could be improved by applying a trailing edge modification. According to Consumer Product Safety Commission [7], a bicycle helmet is designed to attenuate impacts to the head of a cyclist in falls while minimizing side effects such as interference with peripheral vision. A cycle helmet should normally be light in weight and provide sufficient ventilation, because cycling can be an intense aerobic activity which ominously raises body temperature, and the head in specific needs to be able to control its temperature. Helmet is one of the compulsory equipment in reducing the injury to the rider head when accident occurs. Firoz Alam et al. [8] stated that it is compulsory for the helmet to be designed perfectly as to increase the safety performance without reducing its performance and the 
comfortable to the user. Wasserman [9] predicted that helmets would reduce concussions by $29 \%$ and skull fractures by $82 \%$. While Spence [10] describes that $80 \%$ of child fatalities would be prevented. Sacks [11] predicted 70\% fall in fatalities and $84 \%$ reduction in head injuries generally.

Wind tunnels are especially used when testing new designs and materials. This is because of their ability to simultaneously account for wind interactions, as well as material and geometric properties. When testing new materials and designs many times these interactions and properties are not fully known, limiting the use of finite element analysis software. Current testing approaches used in the bicycle racing production employ mainly wind tunnel testing for aerodynamic studies. According to Bell et al. [12], like most engineering projects each wind tunnel is unique and designed for a specific purpose, giving each wind tunnel different sizes, speeds, and Reynolds Numbers. Barlow et al. [13] stated that wind tunnels are simply hollow tubes; at one end, they have powerful fans that create a flow of air inside the tunnel. Some tunnels are desktop-sized and good for testing only very small objects. Other tunnels are huge structures in which engineers test full-size aircraft and cars. Although the test materials remain motionless, swift airflow inside the tunnel makes it seem as though objects are moving.

\section{METHODS}

\section{A. Wind Tunnel Basic Operation}

This inlet wind tunnel is approximately measured $3 \times 3 \mathrm{~m}$. Meanwhile the test section is $1 \times 1 \mathrm{~m}$. With the length of $2.5 \mathrm{~m}^{2}$, the maximum speed could reach until 50 meter per second. Reaching the maximum power $75 \mathrm{HP}$, it is also equipped with 6 component of external balance. The flow velocity in low subsonic wind tunnel is of the Mach number range of zero till 0.3. Viscous and inertial forces are dominant while compressibility effects are negligible. The UPM wind tunnel is an open circuit tunnel. The CAD drawing for the UPM wind tunnel is shown in Fig. 2 and Fig. 3. Open-circuit tunnel is the first type of wind tunnel built. This tunnel is usually referred to as an Eiffel Type. This type of wind tunnel consists of a nozzle, a test section, a diffuser and a driving unit. The principle work of this wind tunnel is a direct sucking of the atmospheric air lying outside of the wind tunnel brought into the tunnel settling chamber and continued to the end of the wind tunnel using a driving unit and then the air is threw away to atmosphere. The position of driving units can be at the downstream end where the tunnel is operated as suction tunnel while otherwise it would be termed a blow down tunnel. The suction tunnel is more preferred in design by a reason of airflow quality.

The subsonic wind tunnel composes several components. The test section is one of the important components where the test model is located. The flow quality in the test section is strongly influenced by other components of the wind tunnel. The components of open-circuit tunnel include an entrance cone, a settling chamber, a nozzle/contraction cone, a test section and a diffuser. While the closed circuit tunnel has additional components to circulate the flow corners, a return passage, breather and some control devices.
A wind tunnel is supposed to produce steady flow with spatial and temporal uniformity at minimum power. Flow uniformity is obtained by placing a honeycomb, screens, and a proper contraction design. Swirl and mean span wise velocity variations can be reduced by using a honeycomb, whereas mean stream wise velocity variations can be reduced by deploying screens. Honeycomb is mandatory for a closed circuit type only, but screens and contractions are required for all type of tunnels (Table I).

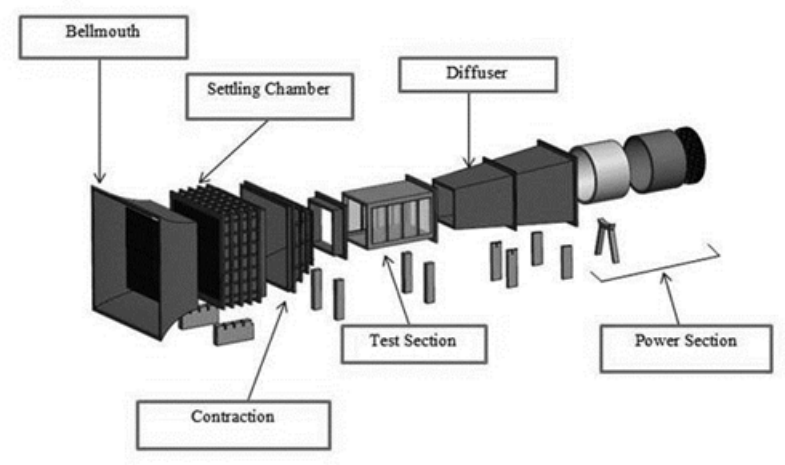

Fig. 2. UPM wind tunnel CAD drawing.

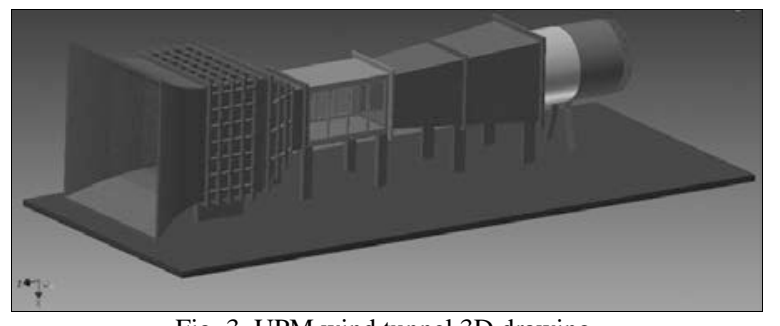

Fig. 3. UPM wind tunnel 3D drawing.

TABLE I: UPM WIND TUNNEL DESCRIPTION

\begin{tabular}{|c|c|}
\hline Wind Tunnel & $\begin{array}{c}\text { OLWT }-1000 \\
\text { (Open Loop Low Speed Wind } \\
\text { Tunnel) }\end{array}$ \\
\hline Serial Number & AEWT $-2001-02$ \\
\hline Test Section Area & $\begin{array}{c}1000 \times 1000 \times 2500 \\
\text { millimeters }\end{array}$ \\
\hline Overall Length & 14.5 meters \\
\hline Overall Height & 4 meters \\
\hline Maximum Speed & 50 meters/second \\
\hline Maximum Power Available & 75 HP \\
\hline Anti-Turbulent Screen & 4 Units \\
\hline Number of Blades & 10 Blades \\
\hline
\end{tabular}

\section{B. Check Calibration}

One way to monitor the flow and thus the need for a repeat calibration is to have a method to quickly check the flow parameters. An example might be a flow-angularity probe that is driven into the flow from a stored position. This system could make completely independent measurements of the tunnel speed and local flow angularity. In order to be utilized during a busy tunnel schedule, this device would need to be quickly and precisely inserted into the airstream. An uncertainty analysis should be performed on this check calibrator to ensure that the quality of the data satisfies the 
requirements.

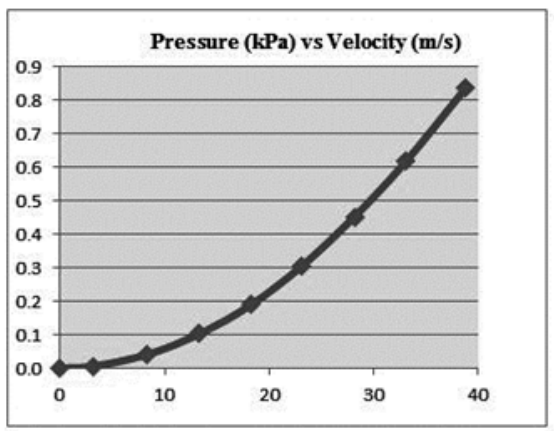

Fig. 4. Calibration result data.

The data reading was obtained during the calibration test. The frequency was set from 0 till $40 \mathrm{~Hz}$ with an increase of 5 $\mathrm{Hz}$ per reading at the wind tunnel control panel. After the value for power had been obtained, graph Pressure $(\mathrm{kPa})$ versus Velocity $(\mathrm{m} / \mathrm{s})$ was plotted. Fig. 4 showed that the reading for pressure increased steadily with the increment of velocity during the calibration.

\section{External Balance System}

External Balance System is designed and developed to fulfil a complete tool required in operating an external balance of a wind tunnel. It provides tools to perform calibrating measurement, controlling model movement, inputting model's data, on-line monitoring and off-line processing. The application runs integrally using database as its internal data storage. Access to the application and data is restricted.

\section{RESULTS}

\section{A. Aerodynamics Wind Tunnel Testing}

The sample was placed in the test section of the wind tunnel on a jig attached to a six component balance system as shown in Fig. 5.

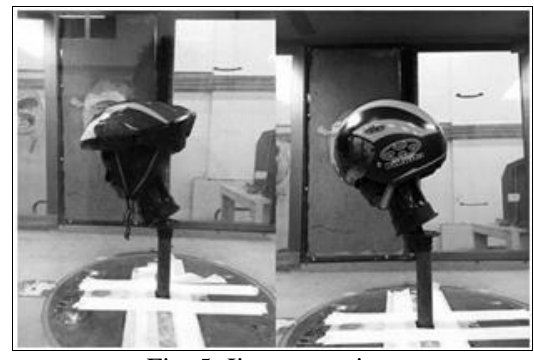

Fig. 5. Jig preparation.

Fig. 6 shows the six component balance entry data that is used to collect the coefficient of drag data for the wind tunnel experiment. Hence, the data was collected using a wind tunnel software DARS. First the profile of the helmet which includes the length, height, weight, wing span, reference area and main aerodynamic chord was set to the profile setup.

The test was conducted in a several constant wind tunnel velocity that best reflects the apparent wind velocity that the rider would experience. In order to measure the drag, the test subject is attached to a load cell in the wind tunnel. Two helmets were acquired for this test. One is a professional cycling helmet while the other is a standard road helmet. The road helmet was used in the test in order to compare the results for an Aero Helmet. The balance system used in the wind tunnel is a six component balance.

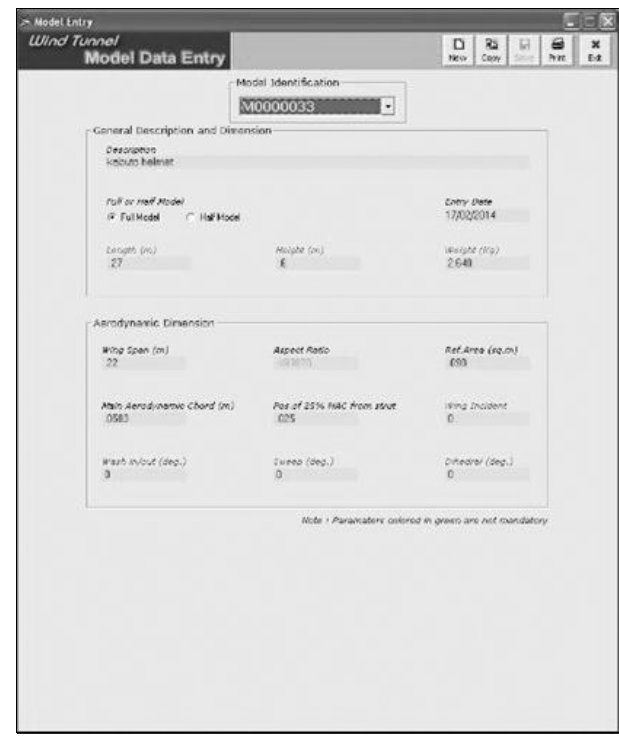

Fig. 6. DARS entry system data.

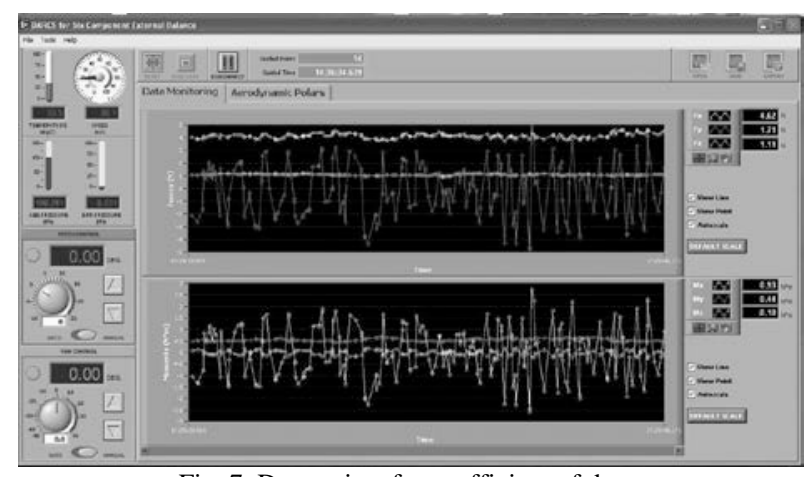

Fig. 7. Data points for coefficient of drag.

Fig. 7 shows the data points for coefficient of drag for the helmet tested collected from DARS System Software. A test sampling of 30 seconds provides enough data points to give confidence in the standard deviations and the error analysis.

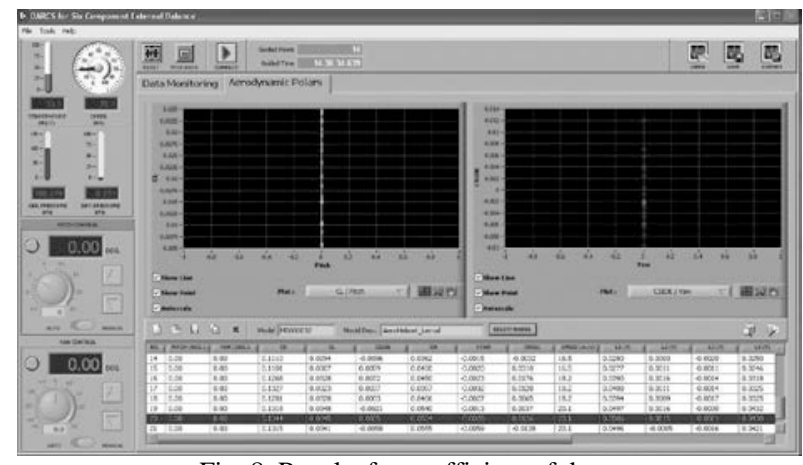

Fig. 8. Results for coefficient of drag.

The test set collects data for 7 different speeds from $3 \mathrm{~m} / \mathrm{s}$ to $15 \mathrm{~m} / \mathrm{s}$. A data set was recorded for each helmet at two different pitch angles which is $0^{\circ}$ and $25^{\circ}$ angle. The test result data is collected from the six component balance DARS system as shown in Fig. 8. Meanwhile, Fig. 9 shows the helmet pitch angle and yaw angle position when the helmet is tested in the wind tunnel. Table II and III shows the 
result for coefficient of drag at $0^{\circ}$ and $25^{\circ}$ pitch angles for standard road cycling helmet and air attack helmet.

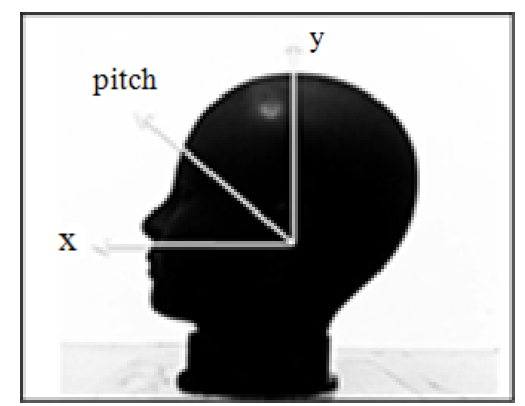

(a)Helmet pitch angle position (side view)

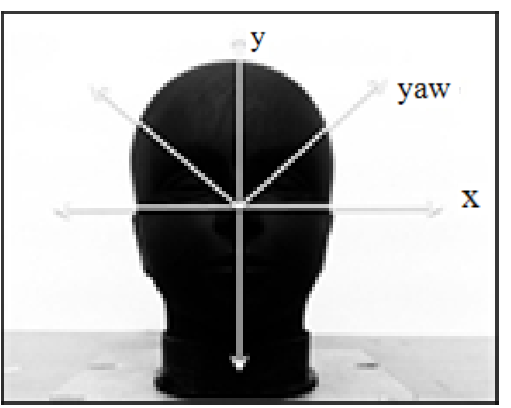

(b) Helmet yaw angle position (front view)

Fig. 9. Helmet angle position.

TABLE II: HELMET WITH $0^{\circ}$ PITCH ANGLE

\begin{tabular}{c|cc}
\hline \multirow{2}{*}{ Speed $(\boldsymbol{m} / \mathbf{s})$} & \multicolumn{2}{|c}{ Drag Coefficient $(\mathbf{C d})$} \\
\cline { 2 - 3 } & Standard Road & Air Attack \\
3 & Cycling Helmet & Helmet \\
5 & 0.0346 & 0.0365 \\
7 & 0.0843 & 0.0610 \\
9 & 0.1265 & 0.1229 \\
11 & 0.1844 & 0.1626 \\
13 & 0.2072 & 0.1862 \\
15 & 0.2359 & 0.2106 \\
\hline
\end{tabular}

TABLE III: HELMET WITH $25^{\circ}$ PITCH POSITION

\begin{tabular}{c|cc}
\hline Speed $(\boldsymbol{m} / \mathbf{s})$ & \multicolumn{2}{|c}{ Drag Coefficient $(\mathbf{C d})$} \\
\cline { 2 - 3 } & $\begin{array}{c}\text { Standard Road } \\
\text { Cycling Helmet }\end{array}$ & $\begin{array}{c}\text { Air Attack } \\
\text { Helmet }\end{array}$ \\
3 & 0.0433 & 0.0328 \\
5 & 0.0927 & 0.0763 \\
7 & 0.1487 & 0.1228 \\
9 & 0.1743 & 0.1571 \\
11 & 0.2021 & 0.1735 \\
13 & 0.2189 & 0.1851 \\
15 & 0.2413 & 0.1937 \\
\hline
\end{tabular}

\section{DISCUSSIONS}

The coefficient of drag results for two different helmet positions that shown in Table II and Table III are tabulated onto graph in Fig. 10 and Fig. 11. From the above analysis, at a pitch angle of $0^{0}$ shows that the coefficient of drag for Air Attack helmet increased slowly compared to the standard road cycling helmet. At a lower speed the standard road cycling helmet and the air attack helmet does not show significant difference between them but as the speed reaches $7 \mathrm{~m} / \mathrm{s}$ the air attack shows better performance compared to the standard road cycling helmet. The worst drag coefficient for this angle is the standard road cycling helmet with coefficient of drag value of 0.2594 at $15 \mathrm{~m} / \mathrm{s}$ while the best performing helmet was the standard road cycling helmet with coefficient of drag value of 0.0346 at $3 \mathrm{~m} / \mathrm{s}$.

In $25^{\circ}$ pitch angle position, the air attack helmet improves significantly compared to the standard road cycling helmet in every speed that tested. The worst performing helmet had a coefficient of drag value of 0.2413 which is the standard road cycling helmet at the speed of $15 \mathrm{~m} / \mathrm{s}$. Meanwhile the best result for coefficient of drag value is 0.0328 by the Air Attack helmet at a speed of $3 \mathrm{~m} / \mathrm{s}$. The graph shows that the Air Attack helmet coefficient of drag increased slowly by the increasing speed compared to the standard road cycling helmet. An aerodynamics helmets do reduce a rider's drag when compared to a standard road helmet in significance speed and angle of pitch.

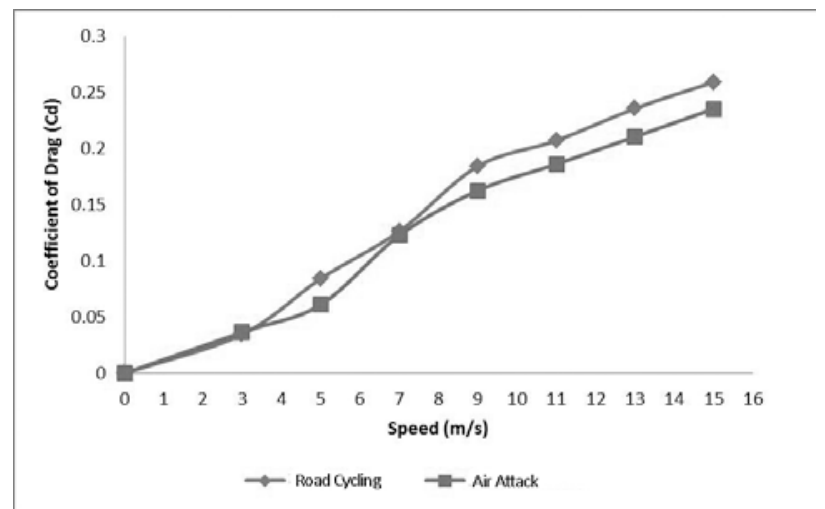

Fig. 10. Helmet with $0^{0}$ pitch angle graph.

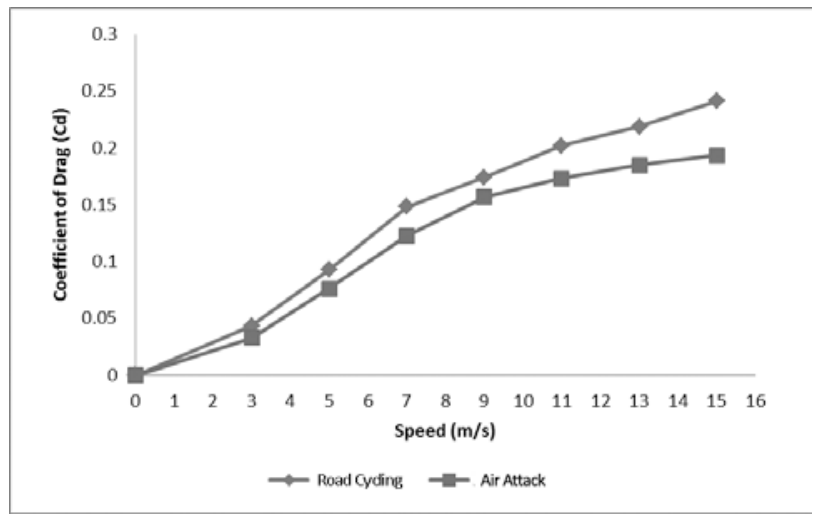

Fig. 11. Helmet with $25^{0}$ pitch angle graph.

An aerodynamics helmets do reduce a rider's drag when compared to a standard road helmet in significance speed and angle of pitch. Cyclist have to take advantage on the best aero position suitable with the angle of pitch while cycling to reduce the drag coefficient since drag is the majority of what a cyclist must overcome in order to move. Aero helmets typically save 30-60 seconds for every hour of riding. The actual time saved for a triathlete depends on how well the helmet smoothest the airflow from the helmet to the middle of the back.

Basically an aero helmet lowers drag to it aerodynamic shape. Drag is the majority of what a rider must overcome in order to move. Hence a reduction in drag could equate to a power savings to the cyclist. According to Martin et al. [14], a professional cyclist is estimated has roughly $22 \mathrm{~N}$ of drag and a power output of 225 Watts, meanwhile an amateur cyclist has $27 \mathrm{~N}$ of drag and a power output of 450 Watts. A typical professional cyclist has close to five pounds of drag, which is $22 \mathrm{~N}$ meanwhile an amateur cyclist has roughly 6 
pounds of drag, which is about $27 \mathrm{~N}$.

The percentage reduction is given by standard road helmet drag minus aero helmet drag and divided by the total drag. Fig. 12 and Fig. 13 show the drag reduction graph for professional cyclist and amateur cyclist at $0^{\circ}$ and $25^{\circ}$ pitch angle. In contrast, the air attack helmet offers drag reduction at a certain angle of pitch and does not performs well at $0^{\circ}$ pitch angle due to its aerodynamic sphere shape. Thus, by not sitting in a good aerodynamic posture, the effects of pressure drag acting on the helmets are greater.

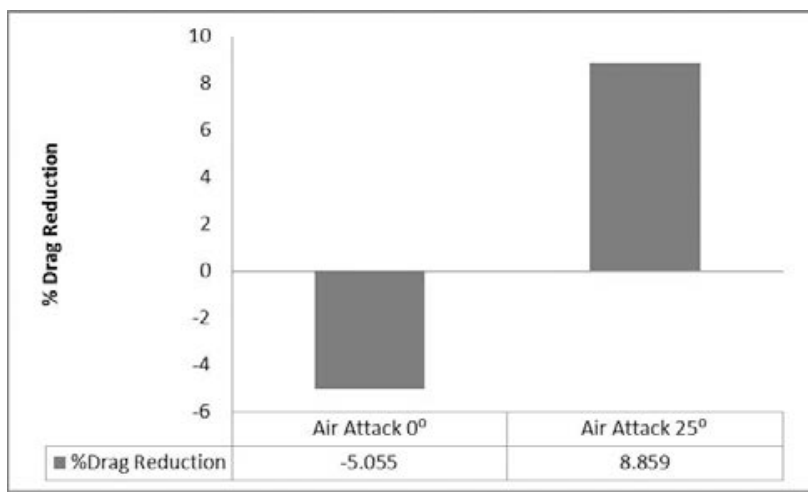

Fig. 12. Drag reduction for a professional rider.

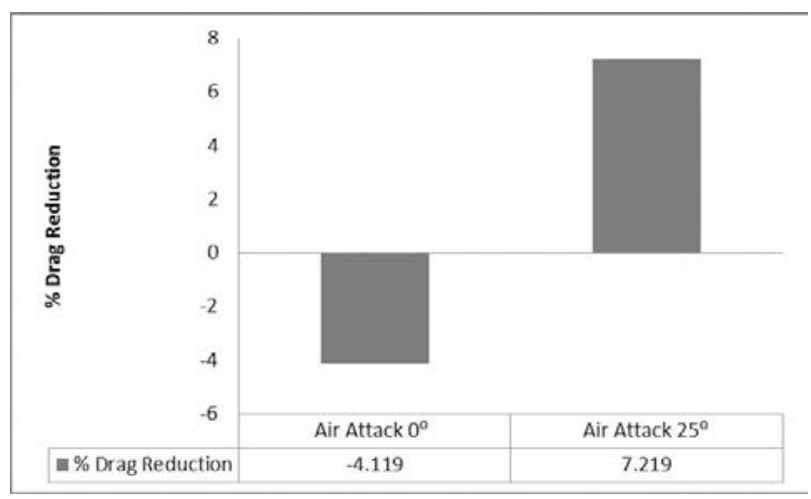

Fig. 13. Drag reduction for an amateur rider.

\section{CONCLUSIONS}

The idea behind aerodynamic helmets is to reduce the overall drag coefficient by smoothing out the frontal surface area and reducing parasitic turbulence created by the model head. An Air Attack helmet was compared to a standard road cycling helmet and it was found that the Air Attack helmet produce less drag in $8 \mathrm{~m} / \mathrm{s}$ speed at $25^{\circ}$ pitch angle. The Air Attack helmet was less effective at low speed and $0^{0}$ pitch angle. Thus, wearing an Air Attack helmet in a good aero position allows the cyclist to cycle at a faster average speed without any increase in energy expenditure.

\section{ACKNOWLEDGMENT}

This research was supported by Universiti Putra Malaysia RUGS 9393700.

\section{REFERENCES}

[1] K. Blair and S. Sidelko, "Aerodynamic performance of cycling time trial helmets,” The Engineering of Sport, vol. 7, no. 2, pp. 371-377, 2008.

[2] B. W. Sims and P. E. Jenkins, “Aerodynamic bicycle helmet design using a truncated airfoil with trailing edge modification," in Proc. ASME 2011 International Mechanical Engineering Congress and Exposition, vol. 6.

[3] P. N. Doval, "Aerodynamic analysis and drag coefficient evaluation of time-trial bicycle riders,” UMW Digital Commons, 2012.

[4] K. Shahbazi, "Pressure drag reduction system with an internal Duct.," Patent US7185944, 2007.

[5] P. Debraux, F. Grappe, A. V. Manolova, and W. Bertucci, "Aerodynamic drag in cycling: methods of assessment," Sports Biomechanics, vol. 10, no. 3, pp. 197-218, 2011.

[6] J. García-López, J. A. Rodríguez-Marroyo, C. E. Juneau, J. Peleteiro, A. C. Martínez, and J. G. Villa, "Reference values and improvement of aerodynamic drag in professional cyclists," Journal of sports sciences, vol. 26, no. 3, pp. 277-286, 2008.

[7] Consumer Product Safety Commission, "Safety standard for bicycle helmets," Final Rule 16 CFR Part 1203, 2006.

[8] F. Alam, H. Chowdhury,Z. Elmir, A. Sayogo, J. Love, and A. Subic, "An experimental study of thermal comfort and aerodynamic efficiency of recreational and racing bicycle helmets," Procedia Engineering, vol. 2, no. 2, pp. 2413-2418, 2010.

[9] R. C. Wasserman and R. V. Buccini, "Helmet protection from head injuries among recreational bicyclists," The American Journal of Sports Medicine, vol. 18, no. 1, pp. 96-97, 1990.

[10] L. J. Spence, E. H. Dykes, D. J. Bohn, and D. E. Wesson, "Fatal bicycle accidents in children: A plea for prevention," Journal of Pediatric Surgery, vol. 28, no. 2, pp. 214-216, 1993.

[11] J. J. Sacks, P. Holmgreen, S. M. Smith, and D. M. Sosin, "Bicycle-associated head injuries and deaths in the United States from 1984 through 1988: How many are preventable?" Journal of the American Medical Association, vol. 266, no. 21, pp. 3016-3018, 1991.

[12] J. H. Bell and R. D. Mehta, "Contraction design for small low-speed wind tunnels," [NASA contractor report], NASA CR-177488, Washington, DC: National Aeronautics and Space Administration, 1988.

[13] Barlow, B. Jewel, W. H. Rae, and A. Pope, Low-speed Wind Tunnel Testing 3rd edition, New York: wiley interscience, 1999.

[14] J. C. Martin, D. L.Milliken, J. E. Cobb, K. L. McFadden, and A. R. Coggan, "Validation of a mathematical model for road cycling power," Journal of Applied Biomechanics, vol. 14, pp. 276-291, 1998.

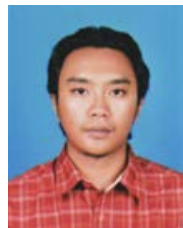

M. N. Abdullah was born in Pahang, Malaysia on 14 March 1987. He got his bachelor degree in aerospace engineering from Universiti Putra Malaysia, Malaysia in 2013.

Upon completing his bachelor degree, he received a Graduate Research Fellowship (GRF) from Universiti Putra Malaysia to further his study in Master of Science (Aerospace Engineering) for two years. Currently he is working in Universiti Putra Malaysia as a research assistant. 